mediastudies.press • Social Media \& the Self: An Open Reader

\title{
Indelicate Communication
}

\section{Erving Goffman}

Published on: Jan 01, 1953

DOI: $10.32376 / 3 f 8575 c b . a f a 803 e 8$

License: Creative Commons Public Domain Dedication (CC-0 4.0). 
IT WAS SUGGESTED that the actor, as a participant in the game of concealment and search, exerts self-control over information about himself which he provides to others. Whether properly or improperly, whether he is or is not detected in his effort, the actor guides some of his communications by an appreciation of their likely effect upon the persons who receive them, this appreciation being guided in turn by the indications that recipients make of the response a proposed line of action will evoke from them. Spontaneous expression of feelings is partly inhibited and appropriate feelings are, in part, conveyed. Accommodation, working acceptance, and tentative harmony are the usual result. If a working acceptance cannot be managed, embarrassment, ill-ease, and confusion are often the result. Withdrawal, conflict, or abrupt alteration in relationships may also occur. In all of these cases, however, the individual knows that he is communicating and knows to whom he is communicating. Although he may be unaware of all that he communicates, he is in a position to exert discretion over a part, at least, of what he conveys, and he is in a position to make use of what he can learn by examining closely the indicated response of recipients to him. If he is not able to exert prior calculation over all that he conveys, he is at least in a position to benefit from a similar incapacity on the part of those who respond to him. Thus, whether we examine cases of working acceptance, withdrawal, conflict, embarrassment, or shift to alternate bases of treatment, we find the general factors of awareness and partial control.

There are a number of marginal situations, however, in which the general factors of awareness and partial control cannot operate, or are not allowed to operate. In these situations, the actor finds himself under direct observation of others but is not in a position to modify his behavior by means of indications of the response he is calling forth from them; corrective feedback is not possible. The strategies which the actor usually employs to protect himself, to protect those about whom he is talking, and to protect the interaction itself, cannot be employed. We shall refer here to indelicate communication arrangements.

One form of indelicate communication occurs in those professional-client relationships for which certain forms of social irresponsibility are heavily institutionalized. Priests, psychiatrists, and lawyers convincingly guarantee a client that certain kinds of reprisals and moral judgments will not be made, no matter what the client conveys to them by word or deed. It is in the client's self-interest to be honest and frank, while at the same time the professional defines himself as someone who cannot and does not take offense. In such a context, it is possible for the client to maintain, of his own free 
will, a communication situation which is so counter to his ordinary protective strategies as chronically to cause him embarrassment.

Another form of indelicate communication occurs in those cases where a person is explicitly obliged to speak honestly if not frankly and at the same time accept the social consequences of having done so. Prenuptual exchanges of confidences provide one example. Another example is found in the technique employed in everyday conversation of turning on a sender, interrupting him, and asking him in a special tone of voice if something he has just said is actually and really true. Evidence given under oath at a trial or hearing is a formal example. (This suggests one reason why these scenes are frequently embarrassing.) In all these cases, the sender is given special warning that any deviation from truth will be fully held against him; he is thus forced to be untactful, to contradict the image he has projected of himself or the image others have projected of themselves.

The two forms of indelicate communication that have been considered-the first where a person is allowed to be untactful and the second where a person is not allowed to be tactful-involve communication situations where the usual amount of strategic control over the linguistic components of messages does not prevail. There are a number of allied forms of indelicate communication which differ from those mentioned in that the sender is not aware that he is not employing the usual amount of calculation and control, or, if he is aware of his lack of control, he is free to exert control yet incapable of doing so.

We have the case where a person involuntarily frees himself from the inclination toward concealment, as in narco-hypnosis (and anesthesia generally), and the case where he more or less voluntarily does the same thing, as in inebriation. An interesting indelicate situation arises when an actor comes under direct observation of a person of whose capacity in this regard the actor is not aware. In everyday terms, recipients of this kind are said to be spying. We are familiar, for example, with the use of dark glasses and veils as a means of concealing from an observed person the fact that he is being observed or as a means of concealing the kind of response that observation of him is arousing. So also, wall mirrors are sometimes used as a means of observing persons who think they are not being observed or, at least, not being observed from that angle. A few examples may be given from the field.

In Dixon it is a very common practice for persons in a cottage to look out of the kitchen window every ten or fifteen minutes or when they hear the croft collies barking. In this way, the inhabitants have ample warning of the approach of 
anyone, and they have time to arrange themselves and the room so that the image of themselves which they wish to communicate to the visitor will not be contradicted by what the visitor sees. This mechanism of forewarning is apparently possible because there are no trees and frequently no neighboring buildings to obstruct the view from a window. A visiting crofter therefore feels that the warning of a knock on the door is not necessary, and frequently neglects to knock. (The visitor may, however, make a slight pause or shuffling sound before entering.) Since the rooms in a crofter's cottage have very little light, it is possible to observe the approach of a visitor without the visitor being able to discover that he is being observed. Crofters enjoy the practice of comparing the facial expressive behavior of a visitor just before he enters the cottage with his behavior just after he enters.

In the primary grades in the Dixon school, pupils sometimes have to withstand scrutiny by visitors. In some cases the stimulus of "personal interaction" with strangers is too much for the pupils to handle with equanamity [sic]; at the same time the "news value" of a visitor to the school may be too great to allow a pupil to turn his attention elsewhere. Some pupils employ the solution of covering their faces with their hand to shield themselves from the gaze of the stranger, while at the same time examining him through the small openings between their fingers.

In Dixon there is a common practice of using a pocket telescope for the purpose of observing one's neighbors without being observed in the act of observing them. In this way it is possible to keep a constant check upon what part of the annual cycle of work a neighbor is engaged in and how rapidly he is progressing with it. It is also possible in this way to keep informed as to who is visiting whom. (This use of telescopes is apparently related to the physical distance between crofts, to the absence of trees, and to the strong maritime tradition of the island.)

In the hotel, the maids would observe the arrival of new guests through the kitchen window. Differences in light intensity made this a one-way possibility and gave the maids a chance to arrive at an initial appraisal of the new guests and to communicate this to one another before it was necessary to have any actual contact with the guests.

Just as persons can be observed without their knowing it, so also their verbal exchanges can be audited without their knowing it. We are familiar with the practice of eavesdropping on conversations, the practice of reading another's mail, and the practice of listening in on a party telephone line. 
In the case of spying and the several kinds of eavesdropping, the sender is prevented from modifying his communication in accordance with its probable effect upon the person who receives it because the sender is not aware (or is not aware in time) that the person is receiving it. Senders may attempt to guard against such an eventuality by trying to behave in such a way as to give no offense to the image any unobserved observer might have of himself or of the sender. $\underline{1}$ This kind of communication superego is especially effective in guiding the conduct of persons who are in fact unobserved by anyone.

An interesting complication in these indelicate communication arrangements occurs when an individual is being spied upon or overheard, knows this to be the case, and tries not to shatter the illusion of the irregular recipient. In this case, the sender may feel that he is in an excellent position to delude the recipient in any desired direction, presumably on the grounds that the recipient will not exercise customary scepticism [sic] in regard to what he oversees or overhears. This constitutes a kind of bluff.

\section{REPRINT}

"Chapter VI: Indelicate Communication" (Erving Goffman, Communication Conduct in an Island Community (PhD diss., University of Chicago, 1953): 90-95) PUBLIC DOMAIN

\section{Footnotes}

1. In Western society there is a moral rule, often followed, that a person who happens into a situation where he can observe others or ovehear them, without this fact being apparent to the others, ought to warn them in some way by means of a tactful cue. This warning allows the others to take precautions against communicating anything that will be offensive in any way. $\bullet$ 